\title{
Article
}

\section{The adventure sports coach: All show and no substance?}

\author{
Gray, P., and Collins, D.
}

Available at http://clok.uclan.ac.uk/12793/

Gray, P., and Collins, D. ORCID: 0000-0002-7601-0454 (2016) The adventure sports coach: All show and no substance? Journal of Adventure and Outdoor Learning, 16 (2). pp. 160-171. ISSN 1472-9679

It is advisable to refer to the publisher's version if you intend to cite from the work. http://dx.doi.org/10.1080/14729679.2015.1123163

For more information about UCLan's research in this area go to http://www.uclan.ac.uk/researchgroups/ and search for < name of research Group>.

For information about Research generally at UCLan please go to http://www.uclan.ac.uk/research/

All outputs in CLoK are protected by Intellectual Property Rights law, including Copyright law. Copyright, IPR and Moral Rights for the works on this site are retained by the individual authors and/or other copyright owners. Terms and conditions for use of this material are defined in the policies page.

\section{CLoK}

Central Lancashire online Knowledge www.clok.uclan.ac.uk

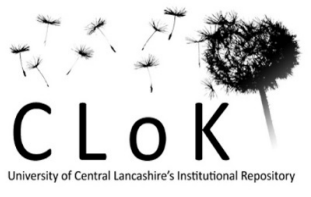


This is a pre-proof corrected manuscript, as accepted for publication, of an article published by Taylor \& Francis in Journal of Adventure Education \& Outdoor Learning on $4^{\text {th }}$ January 2016, available online:

http://www.tandfonline.com/doi/full/10.1080/14729679.2015.1123163

PLEASE REFER TO THE FINAL PUBLISHED VERSION FOR CITING PURPOSES

The Adventure Sports Coach: All show and no substance?

Paul Gray University of Central Lancashire pgray1@uclan.ac.uk

Dave Collins University of Central Lancashire djcollins@uclan.ac.uk 


\begin{abstract}
The primary objective of this research was to establish the range of interpersonal strategies, tools and techniques used by Adventure Sports Coaches (ASCs) to influence participants' actions and behaviours, and determine where these strategies were acquired. An interpretative approach was employed using semi-structured interviews with a convenience sample of expert paddlesports coaches $(\mathrm{N}=4)$. Interpretative Phenomenological Analysis was used to get close to the data and identify salient topics. Five themes were subsequently identified as fundamental to effective coach-participant interaction: appropriate environment, stories told, knowing the participant, formal training and situational context. The implications are that whilst ASCs have well-developed intuitive social engagement skills, these are not consciously or declaratively employed in coaching sessions, nor are they used at strategic levels to enhance participant development. Therefore, a multi-layer approach is recommended to help ASCs access and employ these skills that has consequences for the education, training and continued professional development of Adventure Sports Coaches.
\end{abstract}

Key words: Coach Education; Adventure Sports; Social Interactions; Paddlesports; Coaching. 


\section{Introduction}

The Adventure Sports Coach's (ASC's) multifaceted role as leader, teacher or coach (Collins \& Collins, 2012) is compounded by the physical, social, emotional and personal development challenges and indeed opportunities of those clients who choose to participate in such adventure sports. The environmental demands and subsequent participants perceived risks further add to the complexity of the ASC's role.

Although practicing ASCs appear highly skilled through the achievement of National Governing Body (NGB) qualifications, the training and assessment of such, predominantly focuses upon procedural knowledge (Martindale \& Collins, 2005) through a technical-rational approach (Schön, 1983). Development of appropriate skills thus allows the demonstration of personal competencies that meet the environmental demands of the activity (Collins \& Collins, 2012). Whilst this might be seen as a means to provide enhanced levels of confidence and trust within our participants it would be a naïve coach who believed that the demonstration of personal competence was the sole influence upon the actions and behaviours of our participants. Indeed, it may be difficult to avoid such effects due to the pervasive and omnipresent coach-participant interaction associated within adventure sports. Furthermore, it is important to recognise that the ASC needs to not only control themselves but their participants, the action and the environment. The controlling of these four variables clearly demonstrates a process that is both dynamic and complex and further adds to the concept that the demonstration of personal competencies by the coach may not be the sole influencing factor upon the actions and behaviours of their participants. 
Given this dynamic complexity, it is evident that the multifaceted role of the ASC is challenging to define: a debate that has a long history and shows no sign of abating. Although not wishing to eschew such definable challenges and purely for the purpose of this investigation, we developed the following simplistic and conditional definition of an ASC:

An Adventure Sport Coach is someone who attempts to positively influence the action and behaviour of participants.

One important route to achieve this is through the manipulation and strategic use of social and interpersonal factors (cf. Stoszkowski \& Collins, 2012). Furthermore the value and purpose of such social and interpersonal factors could operate on a number of levels, each with increasing potential and purpose. As such, the first level of interaction may be one of social engagement with general conversation and courteous exchanges of non-specific content or focus. The next level however may elicit credibility and recognition, and as such promote a sense of trust and confidence amongst the participants'. The final level of interaction becomes more individualized with a focus upon how previous interactions can be utilised for the future development of participants'. As such, use of this continuum (social engagement credibility - individualization) would appear to offer the ASC with a structure for the development and use of interpersonal factors in positively influencing the action and behavior of their participants'.

Therefore, reflecting on the issues identified earlier and the general definition above, our first aim was to investigate what interpersonal strategies, tools and/or techniques the ASC utilises in an attempt to influence the participants' action and 
behaviour. Further enquiry as to how, when and why such strategies are utilised was a second question examined since, due to the dynamic nature of the adventure environment, a completely proactive and systematic approach would not be possible. The third and final strand of this enquiry was to investigate where the coach had developed such strategies and whether this was through a formal training process, personal or vicarious experience, or a combination of all three.

\section{Method}

\section{Design}

An Interpretative Phenomenological Analysis (IPA) approach was utilised and data collected through four semi-structured interviews where detailed accounts of participants' lived experiences were gathered through the elicitation of stories (Smith, Flowers, \& Larkin, 2009). Importantly, the use of this approach sought to solicit participant views without the potential bias of priming through overly structured questions. As such, we wished to learn what participants would spontaneously report, rather than what they might remember or create when prompted.

\section{Participants}

Observing IPA guidelines (Smith \& Osborn, 2008) a homogenous and purposefully sampled group of four highly qualified British Canoe Union Coaches with a mean age of 42.5 years were utilised in one-to-one semi-structured interviews. The interviewer who as a British Canoe Union Level 5 Coach of 12 years had personal paddle 
experiences spanning 25 years in an eclectic range of craft including white water kayak, open canoe, marathon racing and white water rafting. Additionally, the interviewer, through a range of professional and personal paddlesport experiences knew all participants. Such experiences extended between 6 and 25 years and assisted the free flowing nature of the interview process through the acquired trust and rapport between the interviewer and interviewee (Sparkes \& Smith, 2009). The second author, also an experienced outdoor and coach educator of over 35 years standing, is a specialist researcher in psychology and coaching. Participants' demographic and relevant experience data are included in Table 1. Irrespective of paddlesport discipline, all participants had completed the British Canoe Union Aspirant Level 5 course. For reasons of confidentiality, pseudonyms are used throughout.

[Table 1 near here]

\section{Instrument}

A semi structured interview schedule was developed comprising of five questions with additional probes for further investigation.

[Table 2 near here]

This approach allowed participants to tell their own story, in their own words, as a functional platform of IPA (Brocki \& Wearden, 2006). Additionally it promoted a sense of purpose and direction but still permitted flexibility and increased depth of 
response, allowing for a unique and personal opinion to be obtained (Cohen, Manion, \& Morrison, 2011).

A pilot interview confirmed the appropriateness of each question and refined the interview technique of the researcher, with only slight semantic amendments made. The delayed response of the interviewee was however considered in more detail as in a number of instances this appeared to be of a significant amount of time. Although slightly unnerved by the silence, observation of the participant suggested that they were in deep thought and the interviewer refrained from interjecting. This supports the work of Corey (2000) who suggests that time is required for participants to frame their opinions and expressions.

\section{Procedure}

The research purpose and protocol was provided to all participants and informed consent obtained. Interviews were conducted individually and in person with each participant informed that they could withdraw from the interview at any time. A relaxed environment was promoted and participants were not privy to the questions prior to commencement. All interviews were recorded using the researcher's iPhone and targeted 40 minutes, (Av $=37$ minutes $)$. Being that the primary focus of IPA is the interpretation of content meaning (Smith et al., 2009) all recordings were transcribed verbatim and without prosodic detail. All Participants received individual transcriptions within 24 hours to confirm accuracy of data.

\section{Data Analysis}


Smith and Osborn (2008) suggest IPA as useful when exploring complex, process or novel situations where no attempt is made to test a predetermined hypothesis and has theoretical roots in phenomenology, hermeneutics and ideography (Smith, 2011) in which the former 'is concerned with the individual's personal perception or account of an object or event, as opposed to an attempt to produce an objective statement of the object or event.' (Smith \& Osborn, 2008, p.53)

Recognising the dynamic nature of this approach, Smythe (2011) comments that it does not set out to solve problems, say why, or provide generalizable truths, but it does take us to places we didn't expect to go. The promotion of thinking is also a key purpose and a two stage interpretation process or double hermeneutic is involved in such that:

'The participants are trying to make sense of their world; the researcher is trying to make sense of the participants trying to make sense of their world' (Smith \& Osborn 2008, p.53)

Utilisation of semi-structured interviews allowed deductive themes to emerge, which reflected both the interview schedule and the researcher's earlier personal narrative. However, inductive themes were also generated and provided a balance of convergence and divergence within the sample, which as Smith (2011) suggests is common within IPA due to the primary detailed analysis of individual cases and subsequent observation of themes across the cases. Furthermore, an idiographic approach to the analysis allowed for detailed observation, and closeness to the data contained in single interviews prior to moving onto more informed data collection, case by case (Smith \& Osborn, 2008). 
Transcripts were read a number of times to allow increasing familiarity of each account. Furthermore on each reading, points of interest or significance were annotated to 'capture the essential quality of what was found on the text' (Smith \& Osborn, 2008, p.68). Subsequent colour coding was then utilised to cluster participant comments and produce tentative theme titles representing rich reflections of their experiences. Connections between the participants' statements and researcher's interpretations were also noted to support the theme titles. Following analysis of all the transcripts, 5 themes of appropriate environment, stories told, knowing participants, formal training and situational context emerged. All of which were checked to ensure connections occurred with the primary source material (actual words of each participant). Extracts of which are presented in Table 3.

(Table 3 near here)

\section{Results and Discussion}

Using an inductive process the data informed five themes for discussion in this paper: appropriate environment; stories told; knowing the participants; formal training; and situational context. Furthermore it was also recognised that as coaches we do have an influence upon our participants, as Carl commented:

Yeah erm, inevitably you are going to have an influence on their paddle sport behaviour both in terms of the direction and feedback you give them with the physical performance of skills and the knowledge they take from those sessions. 
However, being able to connect with those influences remained beyond the explicit skills of the coaches interviewed for this paper and illustrates the need for more understanding in this area. The following themes show what some of those influences are, how they manifest in practice, but that despite their potential to enhance the coaching environment they exist beyond the declarative use of many coaches.

\section{Theme One: Appropriate Environment}

Creating an appropriate environment was discussed across all participants, the importance of which was emphasized by Alan, 'its kind of everything isn't it' and Carl, 'its absolutely imperative that we set the tone'. Although Dave commented, 'there isn't one appropriate coaching environment' it was deemed that setting an appropriate environment was paramount within developing trust, with a requirement to involve interpersonal skills as well as personal competence skills.

Well that comes back to that trust and friendship or bond that you're building with them. And if you don't get that...its going to be more difficult when things start going wrong erm...if they go wrong. (Dave)

If we are setting people up to go into hazardous and challenging environments then we need to ensure that they not only have the hard skills but have the inter personal skills to support each other erm......and go into and come out of those environments safely with a sense of success and enthusiasm for it and not to be put off by it. (Carl) 
Recognising that an appropriate environment, whatever that may be, was important to the coaches, further probing allowed for how this was done to be explored. Dave initially saw this as a relatively simple process of 'being genuine, being honest and being helpful, and sympathetic'. However, he later suggested that it was a complex matter as the interpretation and identity of such qualities will vary across participants' such that 'different learners look for different signs, they'll look for different cues'. Furthermore, Dave also commented that the timing of when participants pick up such signs further adds to the complexity of creating an appropriate environment.

I think, I think, I think its got to be there before the, I think its got to be there from the point that someone wants, they are not going to want to engage, you are not going to have a start of the day....if your....yeah your not going to have a start of a day...very often... if you don't have an appropriate environment or the signs of an appropriate before you even get there.(Dave)

Furthermore, the creating of an environment before getting on the water through informal discussions may begin as early as the drive to the venue.

On the drive up I will be asking them questions about what they want, what they do, getting to know them, and then linking back to if somebody said I'm from Nottingham I'd say, I would quickly think right, Nottingham, Holme Pierre Point, have you been to Matlock, have you been to, do you know these areas, do you know these paddlers you know, then if somebody says err I went to college in, I don't know Devon, I'd be like right what's down in Devon and you're building that bond and that supportive environment (Alan) 
Although the discussion above focuses primarily within a kayaking context, as may be the assumption, this was not the case across all participants. Demonstration of this is provided in the following extract where physical appearance, language used and conversation topic have been considered as mediators for in this case, setting the scene before getting on the water.

When I'm teaching different people I think a little bit about err even from like I think about when I get changed, and where I get changed I think about the kind of equipment I'm gonna wear erm to sort of err... maybe look, look, look less physical and be a little less physical, you know err try and maybe sit slightly if I'm doing a briefing at the start of the day, just sit a little bit more kind of shoulders down just try and bring people in, talk a little bit quieter erm and... break the ice with a little bit of, sometimes just some silly chat you know like err, you been watching a little bit of 'Eastenders', just stupid stuff or Strictly Come Dancing is my favorite in the Winter, coz it makes everyone laugh a bit, I think it breaks the ice, lets people in erm and you know maybe compliment them on various bits of equipment they've got just to try and get them into that sort of zone, rather than think, you stood there with your shoulders back and your thousand pound Kokatat dry suit on and your knives, you know. Just trying to... sort of bring it down to their level a little bit more erm and I also think about the words... in the language that's used, not too kind of direct or anything, just try and sort of, set that little nice scene before you get on erm... (Bob) 
How we create, or indeed, what is an appropriate environment is a complex consideration with the when and how coaches do this being multifaceted. How participants perceive such timings and techniques of the coach adds further complexity to the process. However, limited mention was made of any on the water activity in contrast to the substantial comments made of early, off the water strategies.

\section{Theme Two: Stories Told}

When asked whether stories were used within their coaching, Alan commented that the purpose of the story varied from the simple fact that 'people want to know a bit about you' to, in Bob's experience, perhaps one of self promotion 'I was just gobbing off about working on the Zambezi coz that's a really easy one to sort of impress people with'. However Dave also commented that the stories told were not intended as a heroic account of previous experiences 'I wouldn't tell a story with that intention, to play the heroic character' and Carl who reflected that 'I'm not interested in sharing my war stories'. In fact only Alan pointed out that he might engage with heroic stories but this tended to be outside of the paddling environment, 'the heroic story, heroic failure stories I tend to leave to car journeys or err the pub or something like that'

Although Bob was 'aware of the positives and negatives of this [telling stories].... and at varying times' the telling of stories might not only be an act of self promotion and/or heroic adventure but perhaps as Dave stated, also used 'because there is a lesson in them' and could consist of 'something about where I've been or how I've used those skills in practice'. Furthermore they may also act as a form of integrity or trustworthiness. 
You know sometimes... credibility is quite a big thing within the world of I think certainly open canoe coaching and people sometimes feel more at ease if... you know you're teaching them something about canoe sailing and then you show them something [the participant is referring to a you tube video clip on their iPhone] and they can clearly see that your sat right there flying along at you know 9 knots, whatever, and they are like oh right ok, there's your sort of your credentials there to back up a little bit of that. (Bob)

Conversely however, Bob commented that stories were sometimes out of the paddling as above context and 'I chat a little bit more nowadays about cycling and the kids over lunch' and that they were 'a little informal...maybe we have broke for lunch, maybe hanging out'.

Although the stories told were not commented upon in great detail, the purpose and value of such was emphasized through the interviews. Furthermore, the content of each story varied with a wide number relating to contexts outside of paddlesport. This is of interest as perhaps stories told outside the paddling context have more impression upon our participants than those told within the paddling context and potentially supports the emergent theme of knowing participants.

\section{Theme Three: Knowing Participants}

Discussion based around knowing participants was prevalent throughout the interviews with a key purpose for this highlighted in the following extract: 
well I think with most learners...by getting to know them and understanding what makes them tick erm......knowing about the things that they enjoy...it, it, we can use metaphors and such likes, to help illustrate points, by getting a better understanding, you will also know what makes them tick in terms of what they'll enjoy and what the won't enjoy erm. (Carl)

It was also noted by Alan 'knowing a little bit about them [the participants], pays dividends'. Clarity on what information the coaches wanted to know about the participants was somewhat challenging as Alan mentioned, 'It can be on anything really' as did Carl, 'we need to know how they see the world'. Furthermore, Dave chose to segment the relationship he has with his participants such that he believed 'So, so...its important to know them within the activity and things that influence that but it, its not necessarily important to know them as a person in their family life or work life'. The majority of coaches often felt it necessary to know something about their participants outside the paddlesport context with Bob reporting, 'I like to try and figure people out, you know. What makes them tick, why are they here.... what's their motivation' however he also appreciated the complexity of such due to participant individuality.

So you know everyone's just... different and I think you know if you can get a bit of the background and get under their skin a little bit you can then figure out potentially the best ways to teach them.

The reasons for knowing the participants was also diverse and not solely based on how the coach might use this information, but also how this could effect the actual 
participants themselves. Carl commented, 'I do find sometimes you are trying to help that person lower their barriers to help them be taught, certainly early on in a new relationship' and that 'from us getting to know them they start to learn to understand and trust us'. Dave also went on to say, 'there has to be an element of knowing them to work with them'.

Interestingly, there were some contrasts in participant views. For example, at one stage Dave commented that 'its not necessarily important to know them [the participants] as a person in their family life or work life'. However, he also previously commented that getting to know their participants was on the basis of social engagement, 'I'm not sure it serves any other than a social, other than a social thing'. This divergence is particularly interesting within the context of the social and interpersonal continuum suggested in the Introduction. We return to this later.

In other cases, there was some indication of a 'deeper use' to such knowledge. For example, Bob, who suggested that knowing the participants outside the kayaking and canoeing context could, provide a metaphorical key to closer interpersonal dynamics and further highlights this underpinning facet of social engagement.

Because sometimes that can unlock a door you know maybe its err there's a load of bikes on their Facebook page and I got a little connection there and I can instantly go, ah you been watching the tour and suddenly the barriers just go wow, and there like wow your into the tour yeah yeah, cool, so why are you doing this kayaking thing, you know and you can just move into that person in a really different way and... I do find sometimes you are trying to help that person lower their barriers to help them be taught, certainly early on in a new relationship. (Bob) 
Throughout all interviews, the topic of knowing the participants was prevalent, and as such further enquiry as to how and when this occurred was explored. Initially, Carl focused this upon the use of observation and discussion, 'I watch them first of all.... and then talk to them'. Dave endorsed this 'the only way I would go about doing that is talking to them'. However, it became apparent that Carl also utilised observations:

well, that's my primary tool [observations] for understanding what they are doing and what I might want to help them modify...... guess it depends.....and I'll start to understand.......I guess their emotional make up and their needs and wants like that.

The use of observation in this extract demonstrates that it might not only be the participants' physical competence that is being observed but also the individual's psychological and emotional make up. Thus suggesting that the coach is getting to know their participants better, albeit from a perceptual point of view.

Furthermore, it was also evident throughout a number of interviews that the observations were not all located in water based competencies, and judgements were sometimes made very early on, even before getting on the water.

By the time they've got their boat to the water, so yeah, watching them, putting on their kit, getting their gear out of their car or out of the van or off the trailer. The way they are interacting with other paddlers, the way they carry themselves, the way they launch their boat, the way they put their spray 
decks on, all those sorts of things. Whether they are procrastinating or.....racing to the water like some sort of spaniel on speed......(Carl)

Additionally, opportunities to get to know the participants were regularly informal, 'I might have an informal chat over a cup of coffee before we actually go and see any performance' (Dave) and not confined to a particular time:

I find its when the groups sort of break out a little bit and you get the chance to maybe carry a boat with somebody to the river, you have a little exchange, maybe driving a shuttle, you end up on a one to one. I thinks its in those one to one times when I get...some of the best err I guess its disclosure from that client. (Bob)

Throughout the extracts or any of the transcribed interviews, few comments were made about getting to know the participants whilst water based. In fact, the majority of time the participants commented about off the water activity, some being at the start of the day and some throughout the day:

You know maybe away from what I've been teaching and we'll talk about...something that's happening on that day, the news and then erm you know in a round about day kind of, you know go round them with kind of a few other questions to find out a bit more about them and then go back into the teaching circle. I think some of the finding stuff out about them in the breaks, the coffee stops, the lunch breaks yeah (Bob) 
Knowing the participants was seen as important for a number of reasons such as breaking barriers and as a form of social engagement. And, as was evident within the previous themes of appropriate environment and stories told, limited mention was paid to getting to know them whilst on the water. However a plethora of examples were provided whilst off the water with observations utilised as a primary strategy at the start of the day. Further strategies were also utilised throughout the day, but once again focused upon off the water opportunities.

\section{Theme Four: Formal Training}

The training and assessment of practicing ASCs has been suggested to predominantly focus upon procedural knowledge (Martindale \& Collins, 2005) through a technicalrational approach (Schön, 1984). As such, and as one of the aims of the research, enquiry as to whether the coaches had been trained in any of the emergent themes was explored. Although the coaches did not directly relate the emergent themes as mediators for influencing participant behaviour. When asked whether in their development as a coach there had been any training or mention of how we might influence our participants Carl responded with 'no I don't think there has'. However, training had been transferred from other formal courses:

I have had training when I was looking after children, pro social, relational types of training that were.......explicit....that were genuine...taught behaviours that I suppose I then made my own work within looked after children, but have recognised the values of those behaviours and transferred them into my coaching side as well. (Carl) 
Furthermore, a number of responses explicitly focused upon how they had observed and copied other coach behaviours and not necessarily within the paddlesport context:

I've taken that through me life and whenever I've come across...another coach, someone involved in training me, a manager erm somebody who I've worked alongside seeing do some good stuff I've always tried to steal that and put it into my coaching toolbox. (Carl)

So I think that for me I definitely had to learn that, I......and I did that through...to some extent through mimicry but...but I was quite...I was quite open ended about where those roll models would come form. Erm so I would I'd look at the world of music and, just as much as I would look at coaches so I would adopt something, I would adopt something from a coach that I would know, but I would also adopt something from a musician that I had seen on stage. (Dave)

I don't ever feel that I've been necessarily taught to do this on a coach course or anything and erm... but I've had some very strong influences upon me... and maybe those influences and the way they've been, whether its a certain way you describe something, it's a certain way you wear your equipment, have kind of sort of seeped through and then maybe I either consciously or subconsciously then use those approaches. (Bob) 
Although the coaches agreed that they have an influence upon participants' behaviour, no specific formal training on how to do this had been received within a paddlesport context. Examples from other contexts were provided along with strategies of observations and mimicry of influential characters, from both within and outside the paddlesport context.

\section{Theme Five: Situational Context}

An additional factor that emerged and is prevalent throughout all the themes presented thus far was the situational context and number of off the water examples:

Well I think I can coach people in lots of different ways and sometimes I might just mumble something to somebody walking up a riverbank and that will seep into them and then I'll actually see that in place, and you're like wow. (Bob)

I find its when the groups sort of break out a little bit and you get the chance to maybe carry a boat with somebody to the river, you have a little exchange, maybe driving a shuttle, you end up on a one to one. (Bob)

Furthermore, a number of comments were also made with regard how and when the coach actually absorbed information from their participants. Although no discussion on what they did with this information was explored, a key factor was the timing of such information gathering in that the majority of situations were once again whilst 
the participants were off the water, and in some cases, a long time before actually getting onto the water:

Oh everything, oh you know, if I could be there early enough I'd watch them get out there car, pick up their bag, walk across the road. I'm a real sucker for having a real good look at people and you know look at all the little bits and bobs of pulling their chair up, do they help other people, do they make everyone a brew, yeah all of, its everything you know. (Bob)

by the time they've got their boat to the water, so yeah, watching them, putting on their kit, getting their gear out of their car or out of the van or off the trailer. The way they are interacting with other paddlers, the way they carry themselves, the way they launch their boat, the way they put their spray decks on, all those sorts of things (Carl)

The coaches are explaining here how they observe their participants in great detail before actually getting onto the water. And although no direct link to how the coaches may be influencing their participants can be made here, what is of interest is whether the participants are also making such early observations. Furthermore, consideration is required as to how these observations may be influencing the environment and subsequent participant behaviours.

The multifaceted nature of how an adventure sports coach may influence the actions and behaviours of their participants is a complex process. However, creating an appropriate environment, whatever that may be, emerged as an important factor in the development of trust and support. This was not only between the coach and their 
participant but also between participants themselves. Furthermore, increased attention should be paid to how the environment is created whilst off the water but not only at the start of the day but throughout the course of the chosen activity. This however suggests that all of the actions and behaviours displayed by the coach may have an influential input and demonstrations of personal competence and procedural knowledge, by the coach, may not be the only contributory factor.

Getting to know their participant was also discussed throughout all of the interviews and the eclectic range of what, why and how to do this only serves to promote the complexity of such a task. However, the predominate methods of observation and discussion focused, once again, upon activity off the water. Although discussions acted as a method of information gathering they were also recognised as a form of social engagement and supported similar values to that of the previously mentioned stories told.

However, and against the three level structure introduced earlier, these interactions seemed only to fill the first two purposes (social engagement and credibility) with only one participant (Bob) hinting at some deeper use. It is important to note that, for the moment, our structure is speculative (although theoretically and experientially grounded) and awaits empirical support. Within the limitations of the investigative format however, it is important to note the almost complete absence of realization in these experienced and well-qualified participants for the greater application of knowledge they have been careful to solicit.

\section{Conclusion}


Although it may be intuitively recognised that coaches influence the actions and behaviours of their participants, clarity of how this may be achieved utilising the proposed 3 levels of social engagement, credibility and individualization requires further exploration. Moreover, it is apparent that the understanding of, and training in, the value and influence of the 3 social interaction levels is limited. As coaches it may be that we are attuned to the first level of interaction (social engagement), but less so as to how these, and those on the next level of interaction (credibility) are understood and utilised to increase level 3 interactions (individualization) amongst our participants'. Thus, on-water use of personal insights employed in combination with careful (although often covert) observation of participant behaviour whilst paddling, could be a key tool for achieving important coaching goals including optimized individual experience and proactive risk mediation. .

Thematic constructs of appropriate environment, stories told and knowing the participants may be a possible starting point to further understand how the coach may influence the participants' behaviour within a paddlesport context. Furthermore the emergence that such factors appear to be more prevalent whilst off the water would deem it necessary to investigate this finding further. Finally, if we are to accept the previous definition of an adventure coach as 'someone who attempts to positively influence the action and behaviour of participants', and that the skills as outlined in this paper are neither consciously nor declaratively accessed or employed, then implications exist for the education and training of coaches per se.

\section{Moving Forwards}


A number of modifications could be made to the research design: for example,

Silverman (2013) suggests data collected through traditional interview is 'manufactured' and approaches that look beyond this require consideration.

Furthermore Warriner and Lavallee (2008) observe that retrospective self-reporting is prone to faulty recall and poor articulation. As such, a more ethnographic approach with observations of in situ coach-participant interactions should be considered as this could lead to the identification of previously unnoticed best practice (Miller, Dingwall, \& Murphy, 2004). Likewise, interviews combined with naturalistic observations might allow for better inferences about the thoughts and feelings of the observed (Lazarus, 1995) and which should consider the views of both the coaches and the participants to allow the mapping of the pathways through which in/congruencies occur.

\section{References}

Brocki, L.M., \& Wearden, A.J. (2006). A critical evaluation of the use of interpretative phenomenological analysis (IPA) in health psychology. Psychology and Health. 21, 87-108. doi: 10.1080/14768320500230185

Canoe England (2014). BCU Level 5. Retrieved from http://www.canoeengland.org.uk/tests-i-awards/coaching-qualifications-courses/bcu-level-5/

Collins, L., \& Collins, D. (2012). Conceptualizing the adventure sports coach. Journal of Adventure Education \& Outdoor Learning, 12, 81-93. doi:10.1080/14729679.2011.611283 
Cohen, L., Manion, L., \& Morrison, K. (2011). Research Methods in Education $\left(7^{\text {th }}\right.$ ed.). London: Routledge.

Corey, G. (2000). Theory and practice of counseling and psychotherapy. (6 ${ }^{\text {th }}$ ed.). Andover: Wadsworth Publishing.

Lazarus, R.S. (1995). Vexing research problems inherent in cognitive-meditational theories of emotion-and some solutions. Psychological inquiry, 6, 183-196. Retrieved from http://www.ebscohost.com 7393637.

Martindale, A., \& Collins, D. (2005). Professional judgment and decision making: The role of intention for impact. The Sport Psychologist, 19, 303-317. Retrieved from http://ebscohost.com 17965496.

Miller, G., Dingwall, R., \& Murphy, E. (2004). Using qualitative data and analysis: reflections on organizational research. In D. Silverman (ed.), Qualitative Research: Theory, Method and Practice (pp. 33-55). London: Sage.

Schön, D. A., (1984). The Reflective Practitioner: how professionals think in action. New York: Basic Books.

Silverman, D. (2013). A very short, fairly interesting and reasonably cheap book about qualitative research. ( $2^{\text {nd }}$ ed.). London: Sage. 
Smith, J.A. (2011). Evaluating the contribution of interpretative phenomenological analysis. Health Psychology Review, 5, 9-27. doi: 10.1080/17437199.2010.510659

Smith, J.A., Flowers, P., \& Larkin, M. (2009). Interpretive Phenomenological Analysis: Theory, Method and Research. London: Sage.

Smith, J.A., \& Osborn, M. (2008). Interpretative Phenomenological Analysis. In J. A. Smith (Ed.), Qualitative psychology, a practical guide to research methods. (2 ${ }^{\text {nd }}$ ed.). (pp. 53-80). London: Sage.

Smythe, L. (2011, December 19) Phenomenolgy. [Video presentation] Retrieved from http://vls.uclan.ac.uk/Play/5375

Sparkes, A., \& Smith, B. (2009). Judging the quality of qualitative enquiry:

Criteriology and relativism in action. Psychology of Sport and Exercise, 10, 491-497. doi:10.1016/j.psych.2009.02.006

Stoszkowski, J., \& Collins, D. (2012). Communities of practice, social learning and networks: exploiting the social side of coach development. Sport, Education and Society, 1-16. doi: 10.1080/13573322.2012.692671

Warriner, K., \& Lavallee, D. (2008). The Retirement Experiences of Elite Female Gymnasts: Self Identity and the Physical Self. Journal of Applied Sport Psychology. 20, 301-317. doi: 10.1080/10413200801998564 
Table 1. Participant Demographic

\begin{tabular}{|c|c|c|c|}
\hline Name & Age & $\begin{array}{c}\text { BCU Paddlesport } \\
\text { Qualification }\end{array}$ & $\begin{array}{c}\text { Number } \\
\text { of years held }\end{array}$ \\
\hline Alan & 43 & Level 5 Inland Kayak & 1 \\
\hline Bob & 39 & $\begin{array}{c}\text { Level 5 Raft } \\
\text { Level 4 Canoe }\end{array}$ & $\begin{array}{l}10 \\
\end{array}$ \\
& & Level 4 Kayak & 10 \\
\hline Carl & 39 & Level 5 Surf Kayak & 14 \\
& & Level 4 Inland Kayak & 17 \\
\hline Dave & 45 & Level 5 Inland Kayak & 10 \\
\hline
\end{tabular}

Table 2. Interview Schedule

\begin{tabular}{|c|c|}
\hline Question & Probes \\
\hline $\begin{array}{l}\text { 1.Tell me about your paddling pathway } \\
\text { from the early days to becoming a level } 5 \\
\text { coach. }\end{array}$ & $\begin{array}{l}\text { Duration, experiences, influences } \\
\text { - What do you do now with respect } \\
\text { your paddle coaching }\end{array}$ \\
\hline $\begin{array}{l}\text { 2.When coaching do you feel you have } \\
\text { an influence on the people you are with? }\end{array}$ & $\begin{array}{l}\text { - How do you influence } \\
\text { - What do you influence } \\
\text { - } \text { Provide examples } \\
\text { - } \text { Are there any additional factors } \\
\text { - } \text { Are these influences trained or } \\
\text { implicit }\end{array}$ \\
\hline $\begin{array}{l}\text { 3. How important do you feel it is to } \\
\text { create an appropriate coaching } \\
\text { environment? }\end{array}$ & $\begin{array}{l}\text { - What sort of environment do you } \\
\text { create } \\
\text { - How do you do this } \\
\text { - Provide examples } \\
\text { - Do you engage in stories of your } \\
\text { own experience }\end{array}$ \\
\hline $\begin{array}{l}\text { 4. Do you get to know the people you } \\
\text { coach? }\end{array}$ & $\begin{array}{l}\text { - Why } \\
\text { - How do you do this } \\
\text { - What information are you seeking } \\
\text { - Provide examples }\end{array}$ \\
\hline $\begin{array}{l}5 . \text { With reference to 'what you do' within } \\
\text { your coaching are there specific times } \\
\text { when these are carried out? }\end{array}$ & $\begin{array}{l}\text { - } \text { Before getting on the water } \\
\text { - Throughout the day } \\
\text { - At the end of the day }\end{array}$ \\
\hline
\end{tabular}




\begin{tabular}{|l|l|}
\hline & $\bullet$ Provide examples \\
\hline $\begin{array}{l}\text { 6. What do you believe are the key } \\
\text { factors, which influence the people, you } \\
\text { coach? }\end{array}$ & $\bullet$ Why \\
\hline
\end{tabular}

Table 3. Summary of Themes and Raw Data Extracts

\begin{tabular}{|c|c|c|}
\hline Theme & $\begin{array}{l}\text { Number of } \\
\text { Participants }\end{array}$ & Selected quotes from participants \\
\hline $\begin{array}{l}\text { Appropriate } \\
\text { Environment }\end{array}$ & 4 & $\begin{array}{l}\text { "so yeah creating a supportive } \\
\text { environment" } \\
\text { "I think its vital" } \\
\text { "make sure they are warm and well fed" } \\
\text { "being genuine. Being honest and being } \\
\text { helpful, and sympathetic" }\end{array}$ \\
\hline Stories Told & 4 & $\begin{array}{l}\text { "people want to know a bit about you" } \\
\text { "yeah, but I'm very aware of the positives } \\
\text { and negatives of this" } \\
\text { "chat a little bit more nowadays about } \\
\text { cycling and the kids over lunch" } \\
\text { "it might be my experience but I tend to } \\
\text { frame as somebody else's experience so it } \\
\text { doesn't become like telling war stories" } \\
\text { "I might share stories because there is a } \\
\text { lesson in them" }\end{array}$ \\
\hline Knowing Participants & 4 & $\begin{array}{l}\text { "trying to find a hook to get them in" } \\
\text { "knowing a little bit about them plays } \\
\text { dividends" } \\
\text { "if you can get a bit of the background" } \\
\text { "knowing about the things that they } \\
\text { enjoy" } \\
\text { "there has to be an element of knowing } \\
\text { them to work with them" }\end{array}$ \\
\hline Formal Training & 4 & $\begin{array}{l}\text { "but the soft skills is something that is just } \\
\text { within most people" } \\
\text { "I think anybody can be a coach, but to be } \\
\text { a good coach there is something else } \\
\text { about you" } \\
\text { "through.... observation really" }\end{array}$ \\
\hline
\end{tabular}




\begin{tabular}{|l|l|l|}
\hline \multirow{5}{*}{} & & $\begin{array}{l}\text { "I don't ever feel that I've been } \\
\text { necessarily taught to do this on a coach } \\
\text { course" } \\
\text { "so in coaching courses has there been } \\
\text { any explicit training in how we change, } \\
\text { how we influence people... No I don't } \\
\text { think there has" } \\
\text { "I think for me I definitely had to learn } \\
\text { that...to some extent through mimicry" }\end{array}$ \\
\hline \multirow{5}{*}{ Situational Context } & $\begin{array}{l}\text { "on the drive up...you are building that } \\
\text { bond" } \\
\text { "nothing I would pinpoint a moment } \\
\text { on...it just happens" } \\
\text { "how I dress and prepare" } \\
\text { "use quite a lot of questioning, maybe } \\
\text { after an event, you know or maybe before } \\
\text { an event" } \\
\text { "mumble something walking up a } \\
\text { riverbank" } \\
\text { "perhaps before we get on the water" } \\
\text { "I might have an informal chat over a cup } \\
\text { of coffee" }\end{array}$ \\
\hline
\end{tabular}

